\title{
ORIGINAL ARTICLE Obesity and age-related alterations in the gene expression of zinc-transporter proteins in the human brain
}

\author{
RH Olesen ${ }^{1}$, TM Hyde ${ }^{2,3,4}$, JE Kleinman ${ }^{2}, \mathrm{~K} \mathrm{Smidt}^{1}$, J Rungby ${ }^{1,5}$ and A Larsen ${ }^{1}$
}

\begin{abstract}
The incidence of Alzheimer's disease (AD) is increasing. Major risk factors for AD are advancing age and diabetes. Lately, obesity has been associated with an increased risk of dementia. Obese and diabetic individuals are prone to decreased circulating levels of zinc, reducing the amount of zinc available for crucial intracellular processes. In the brain, zinc co-localizes with glutamate in synaptic vesicles, and modulates NMDA receptor activity. Intracellular zinc is involved in apoptosis and fluctuations in cytoplasmic $\mathrm{Zn}^{2+}$ affect modulation of intracellular signaling. The ZNT and ZIP proteins participate in intracellular zinc homeostasis. Altered expression of zinc-regulatory proteins has been described in $A D$ patients. Using microarray data from human frontal cortex (BrainCloud), this study investigates expression of the SCLA30A (ZNT) and SCLA39A (ZIP) families of genes in a Caucasian and African-American sample of 145 neurologically and psychiatrically normal individuals. Expression of ZNT3 and ZNT4 were significantly reduced with increasing age, whereas expression of ZIP1, ZIP9 and ZIP13 were significantly increased. Increasing body mass index (BMI) correlated with a significant reduction in ZNT1 expression similar to what is seen in the early stages of AD. Increasing BMI also correlated with reduced expression of ZNT6. In conclusion, we found that the expression of genes that regulate intracellular zinc homeostasis in the human frontal cortex is altered with increasing age and affected by increasing BMI. With the increasing rates of obesity throughout the world, these findings warrant continuous scrutiny of the long-term consequences of obesity on brain function and the development of neurodegenerative diseases.
\end{abstract}

Translational Psychiatry (2016) 6, e838; doi:10.1038/tp.2016.83; published online 14 June 2016

\section{INTRODUCTION}

Worldwide, populations are growing older. ${ }^{1}$ A downside to increased longevity is the growing number of dementia cases, most commonly in the form of Alzheimer's disease (AD). ${ }^{2}$ Today, 36 million people suffer from $A D$, with the expectation that this number will double within just 20 years $^{3}$ implosing a huge socioeconomic burden on societies.

Most cases of AD are sporadic, occurring late in life. The main risk factors of sporadic $A D$ are advanced age ApoE genotype and diabetes. $^{4,5}$ Moreover, several studies find that obesity per se increases the risk of developing dementia. ${ }^{6-11}$ There is a correlation between obesity in early and midlife and the subsequent development of $A D$ in later years. Interestingly, obesity in the elderly might, in fact, be protective. ${ }^{7}$ The link between neurodegeneration and obesity should attract concern from the healthcare communities as there is a dramatic world-wide increase in average body weight in recent decades. ${ }^{12,13}$

The mechanisms linking metabolic dysfunction and obesity to neurodegenerative processes are unclear. A high incidence of cardiovascular disease, persistent low-grade inflammation and low levels of zinc in the blood are common in diabetic and obese individuals. ${ }^{14-18}$ Both circulating and erythrocyte zinc levels are reduced ${ }^{16}$ in obesity and there appears to be a direct link between zinc deficiency and obesity-related comorbidities such as insulin resistance. ${ }^{15,17,18}$ Inflammation and atherosclerosis likely explain part of the epidemiological linkage between dementia, metabolic disease and obesity. ${ }^{19,20}$ The increased risk of $A D$ in diabetic individuals, independent of body weight, is a subject of great interest.

As the human body does not sequester stores of zinc for later use, plasma zinc becomes the main pool of readily available zinc. Consequently, hypozincemia potentially could affect the zinc homeostasis throughout the body. The relationship between brain zinc levels and obesity are unknown. In AD brains, the literature is inconclusive and varies dependent on the anatomical localization of the sample. The areas rich in zinc include hippocampus and neocortex, especially layers III and IV, in which the so-called zincenriched neurons are found. ${ }^{21}$ Moreover, zinc binds to amyloid plaques $^{22}$ and there have been reports of both high ${ }^{23,24}$ and low ${ }^{25,26}$ zinc content in AD brains compared with healthy brains. ${ }^{27}$

The functional relationships between zinc homeostasis, the amount of zinc present in the human brain and the onset of neurodegenerative processes require additional inquiry. In zincenriched neurons, the amount of free synaptically active zinc is controlled by the ZNT3 transporter. ${ }^{28}$ The ZNT3 downregulation has been linked both to AD pathology and to normal aging of the brain. ${ }^{29,30}$ Within synaptic vesicles, free zinc co-localizes with glutamate, and experimental studies indicate that the liberation of zinc from zinc-enriched neurons can modulate NMDA activity. ${ }^{31}$ The ZnT3-knockout mice exhibit cognitive difficulties with increasing age $\mathrm{e}^{30}$ and moderate dietary zinc deficiency has been linked to cognitive deficits in humans. ${ }^{32}$ The role of vesicular zinc in amyloid pathology has been tested by cross-breeding the Tg2576 AD mice with ZnT3KO mice. ${ }^{33}$ This experiment confirmed

${ }^{1}$ Department of Biomedicine, Aarhus University, Aarhus, Denmark; ${ }^{2}$ Lieber Institute for Brain Development, Johns Hopkins Medical Campus, Baltimore, MD, USA; ${ }^{3}$ Department of Neurology, Johns Hopkins University School of Medicine, Baltimore, MD, USA; ${ }^{4}$ Department of Psychiatry and Behavioral Sciences, Johns Hopkins University School of Medicine, Baltimore, MD, USA and ${ }^{5}$ Center for Diabetes Research, Gentofte University Hospital, Hellerup, Denmark. Correspondence: Dr A Larsen, Department of Biomedicine, Aarhus University, Building 1242, Wilhelm Meyers Allé 4, 8000C Aarhus, Denmark.

E-mail: al@biomed.au.dk

Received 26 September 2015; revised 22 March 2016; accepted 31 March 2016 
Table 1. Demographics of the adult ( $>18$ years of age) subjects of African-American and Caucasian descent obtained from the online BrainCloud data set.

\begin{tabular}{|c|c|c|c|c|c|}
\hline$B M I$ group & $\mathrm{n}$ & Race & Sex & Age & $B M I$ \\
\hline Underweight $(<18.5)$ & 4 & $1 \mathrm{CAUC} / 3 \mathrm{AA}$ & $1 \mathrm{~F} / 3 \mathrm{M}$ & $38.58(20.2)$ & $17.52(1.2)$ \\
\hline Normal (18.5-24.99) & 39 & $20 \mathrm{CAUC} / 19 \mathrm{AA}$ & $17 \mathrm{~F} / 22 \mathrm{M}$ & $39.91(17.6)$ & $22.2(1.9)$ \\
\hline Overweight (25-30) & 41 & $21 \mathrm{CAUC} / 20 \mathrm{AA}$ & $5 \mathrm{~F} / 36 \mathrm{M}$ & $44.2(14.1)$ & $27.42(1.35)$ \\
\hline Obese $(>30)$ & 61 & $20 \mathrm{CAUC} / 41 \mathrm{AA}$ & $23 \mathrm{~F} / 38 \mathrm{M}$ & 41.79 (13.9) & $38.61(9.5)$ \\
\hline NA & 3 & NA & NA & NA & NA \\
\hline Total & 148 & $63 \mathrm{CAUC} / 85 \mathrm{AA}$ & $46 \mathrm{~F} / 102 \mathrm{M}$ & $42.1(15.1)$ & $30.4(9.78)$ \\
\hline
\end{tabular}

a role for vesicular zinc in plaque formation as the resulting double-mutant mice displayed a significantly reduced plaque load. However, the mechanisms linking zinc, plaque formation and cognitive performance remains elusive. Dietary zinc restriction paradoxically leads to increased plaque formation in the APP/PS1 $A D$ mouse. ${ }^{22}$ Similarly, zinc supplementation reduced plaque formation in an AD model. ${ }^{34}$ In that experiment, zinc supplementation also coincided with reduced cognitive performance. Others have shown that alterations in intracellular zinc might also disturb microtubular function and the formation of neurofibrillary tangles. ${ }^{35}$

Overall, most experiments with zinc supplementation seem to improve cognitive performance, ${ }^{36}$ but the diversity in literature on this topic highlights the importance of a tightly balanced zinc regulation.

Alterations in intracellular zinc homeostasis may be produced by alterations in the ZNT or ZIP proteins. The ZIP proteins regulate zinc uptake from the extracellular environment as well as zinc release from intracellular stores. In contrast, the ZNT proteins redirect zinc to the extracellular space and provide zinc for synaptic vesicles (ZNT3) and other organelles.

Altered gene or protein expression of several ZNTs has been associated with AD pathology. Although ZNT3 expression is downregulated, other ZNT transporters are upregulated. In hippocampus, there are reports of increased protein levels of ZNT4, ZNT6 and ZNT1. ${ }^{37,38}$ The ZNT1 transporter is the only member of the SCLC30A family actively transporting zinc from the cytoplasm to the extracellular compartment. Post-mortem analyses have shown that ZNT1 expression is reduced in $A D$ as well as in patients suffering from mild cognitive impairment. ${ }^{38}$ On the other hand, patients with fulminant $A D$ displayed an increased expression of ZNT1.38

On the basis of previous studies, we hypothesize that a reduced level of ZNT1 in early-stage dementia constitutes a possible defense mechanism against systemic or local zinc deficiencies.

Utilizing cDNA microarray data from the prefrontal cortex of 145 neurologically and psychiatrically sound individuals, the relationship between body mass index (BMI), a standard measurement of weight/height relation and the ZIP and ZNT gene expression was examined. Furthermore, we investigated the relationship between the expression of these genes in the frontal cortex, gender or race, comparing African-American to Caucasian cohorts.

\section{MATERIALS AND METHODS}

The data used in this study were obtained through the BrainCloud database (http://braincloud.jhmi.edu/) courtesy of the Lieber Institute of Brain Development. We used microarray data on post-mortem dorsolateral prefrontal cortex (corresponding to Broadman's areas number 9 and 46) from individuals without any psychiatric or neurological disease. The microarray expression data were obtained using the Illumina Oligoset (HEEBO7) chip, processed and expressed as previously described. ${ }^{39}$ All tissue collection was performed with informed consent obtained from the next of kin. All the data were subsequently anonymized in accordance with the rules and regulations of the National Institute of Health (using protocol 90-M-0142)

\section{BrainCloud demographics}

BrainCloud contains non-neurologic/non-psychiatric controls up to 78 years of age. None of the subjects had any pathological findings consistent with $A D$, or other neurological diseases. In the present study, we excluded all individuals under the age of 18, four of Asian descent and five of Hispanic descent. Focusing on obesity per se, four individuals with known diabetes and three individuals with unknown BMI were excluded leaving 145 (63 Caucasians and 85 African Americans) subjects for the study. For a detailed description of the demographics of these subjects, please see Table 1.

\section{Genes}

All genes of the SLC30A/39A families available in BrainCloud were analyzed in this study. Accordingly, all members of the SLC30A family (ZNT1-ZNT10) were analyzed, as well as most members of the SCL39A family with the exception of the ZIP5, ZIP6 and ZIP12 genes that are not included on the Illumina HEEBO chip.

\section{Statistics}

Statistical analyses were done using $R$ version 3.0.2, (R Foundation for Statistical Computing; http://www.r-project.org/). The data were considered normally distributed from examination of the quantile-quantile plot (QQ-plot), linear regression analysis was performed to assess the contributions of age on mRNA expression levels. The variation in mRNA expression of each gene was analyzed using BMI and age as continuous variables. The interaction between the age and BMI for each gene was compared using multiple regression analysis (Table 2). The comparison between African Americans and Caucasians, males and females, were performed using Student's $t$-test as when data were normally distributed, when not normal distributed Wilcoxon rank-sum test was used. Student's $t$ test is written as $t$ (degrees of freedom) $=, P=$. Wilcoxon rank-sum is written as $W=$ rank sum, $P=0$. For all analyses, level of statistical significance was set at $P \leqslant 0.05$.

\section{RESULTS}

Increasing BMI results in a decrease in the mRNA expression of ZNT1 and ZNT6

Looking at BMI as a continuous variable revealed a statistically significant inverse correlation between ZNT1 and ZNT6. For ZNT1: ZNT1 expression $=-0.007507 \times \mathrm{BMI}+0.550087, \quad \mathrm{~F}(1,143)=9.912$, $R^{2}=0.065, P<0.005$. For ZNT6: ZNT6 expression $=-0.012496 \times$ $\mathrm{BMI}+1.065286, \mathrm{~F}(1,143)=4,681, R^{2}=0.0319, P=0.032$. There is an inverse correlation between mRNA expression and increasing BMI (Figures $1 \mathrm{a}$ and $\mathrm{b}$ ). The mRNA expression of the rest of the SLC30 family, that is, ZNT2, ZNT3, ZNT4, ZNT5, ZNT7, ZNT8, ZNT9 and ZNT10 did not correlate with BMI. In the SLC39A family, increasing BMI did not correlate with the mRNA expression of the ZIPs examined, that is, ZIP2-4, ZIP7-11 and ZIP13-14. We found interaction between BMI and age for the genes ZIP1 and ZIP11. 
In ZIP1, we found an interaction between age and BMI, and used this in the regression, giving us a significant relationship between ZIP1, age and BMI: ZIP1 $=-0.0108695 \times$ age $-0.0213034 \times \mathrm{BMI}$ $+0.0005721 \times($ Age $\times \mathrm{BMI})+0.0451270, \mathrm{~F}(3,141)=4.98, R^{2}=0.09581$, $P=0.0026$; giving us a combined decrease with age and $\mathrm{BMI}$ for ZIP1.

In ZIP11, we did not find any relationship with gene expression and age or BMI; ZIP11 $=-0.0089901 \times$ Age $-0.0149509 \times \mathrm{BMI}$ $+0.0004191 \times($ Age $\times \mathrm{BMI})+0.4999, \quad \mathrm{~F}(3,141)=2.508, \quad R^{2}=0.05065$, $P=0.06$.

Table 2. Interaction between age and body mass index, in relation to analysis of each zinc-transporter gene

\begin{tabular}{ll}
\hline Gene name & P-value \\
\hline ZNT1 & 0.46 \\
ZNT2 & 0.732 \\
ZNT3 & 0.48 \\
ZNT4 & 0.07 \\
ZNT5 & 0.49 \\
ZNT6 & 0.772 \\
ZNT7 & 0.34 \\
ZNT8 & 0.837 \\
ZNT9 & 0.2 \\
ZNT10 & 0.7 \\
ZIP1 & $0.0143^{\mathrm{a}}$ \\
ZIP2 & 0.0728 \\
ZIP3 & 0.202 \\
ZIP4 & 0.689 \\
ZIP6 & 0.366 \\
ZIP7 & 0.872 \\
ZIP8 & 0.679 \\
ZIP9 & 0.656 \\
ZIP10 & 0.116 \\
ZIP11 & $0.0451^{\mathrm{a}}$ \\
ZIP13 & 0.648 \\
ZIP14 & 0.315 \\
\hline SIgnicant interion
\end{tabular}

${ }^{\mathrm{a} S i g n i f i c a n t}$ interaction. Evaluated using multiple regression.
The mRNA expression of ZNT3 and ZNT4 is gradually reduced throughout adulthood, whereas the expression of ZIP9 and ZIP13 gradually increases

Looking at each gene individually, a statistically significant reduction in the mRNA expression of ZNT3 (Figure 2a; ZNT3 expression $=-0.005144 \times$ Age $+0.047144, \quad F(1,146)=8.456, \quad R^{2}=$ $0.05475, P<0.004$ ) and ZNT4 (Figure 2b; ZNT4 expression $=$ $-0.005535 \times$ Age $\left.-0.123892, \mathrm{~F}(1,146)=4.384, R^{2}=0.029, P=0.038\right)$ was seen with increasing age throughout adult life ( $>18$ years), whereas the expression pattern of the remaining eight efflux transporters of the SLC30A family was unaffected. In the SLC39A family of zinc influx proteins, there was a statistically significant upregulation of ZIP9 (ZIP9 expression $=0.003454 \times$ Age -0.435929 , $\left.\mathrm{F}(1,146)=9.515, R^{2}=0.06118, P=0.002\right)$ and ZIP13 (ZIP13 expression $=0.002995 \times$ Age $-0.236005, \quad F(1,146)=5.313, \quad R^{2}=0.03511$, $P=0.023$ ) with increasing age (Figures $2 c$ and $d$ ). Likewise, there were decreased levels of ZIP10, (ZIP10 expression $=-0.008570 \times$ Age+0.964997, $\left.\mathrm{F}(1,146)=4.632, R^{2}=0.03075, P=0.033\right)$

There was no relationship between age and the mRNA expression of ZIP2-4, ZIP7-8 or ZIP14.

Smoking does not affect mRNA expression of zinc-regulatory proteins of the SLC30A (ZNT) and SLC39A (ZIP) families

The relationship between smoking status at the time of death on the gene expression of the SLC3OA (ZNT) family and most of the SLC39A family, that is, ZIP1-4, ZIP7-11 and ZIP13-14 was examined without any significant findings on the mRNA expression of either class of zinc-regulatory proteins.

Analyses of biological variations in the mRNA expression of zinc-regulatory proteins revealed both sex differences and differences between African Americans and Caucasians

We found that men exhibited a statistically, significantly higher expression of ZNT4 $(t(62.446)=-3.7279, P<0.0004$; Figure $3 a)$ than women in this study as well as statistically, significantly lower expression of ZIP1 $(t(65.14)=2.9317, P=0.01241)$ and ZIP8 $(t(68.837)=-2.9317, P=0.009$; Figure $3 b)$. Comparing the gene expression pattern of zinc-regulatory proteins between racial
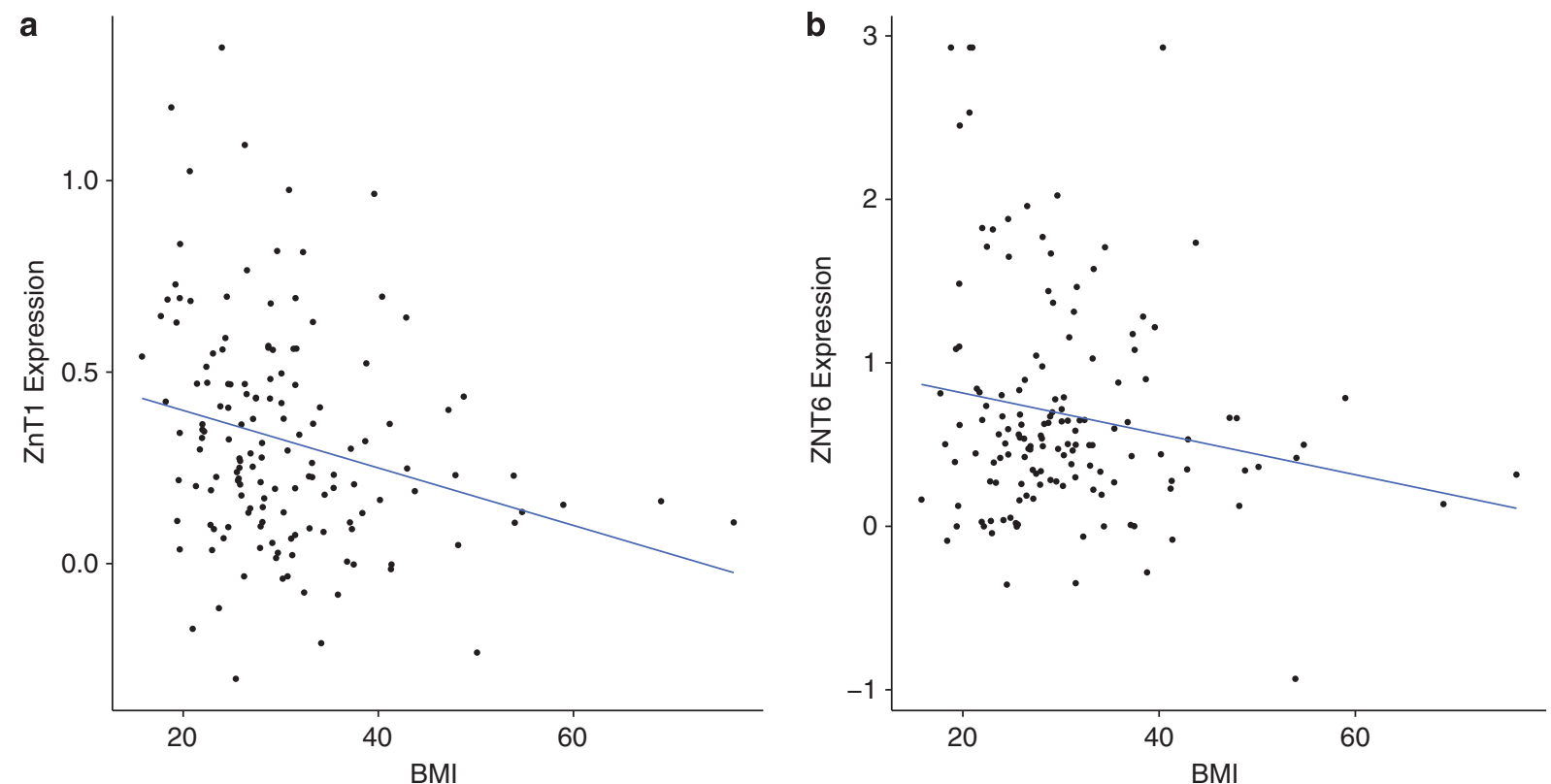

Figure 1. (a and $\mathbf{b})$ On the $x$ axis, BMI $\left(\mathrm{kg} / \mathrm{m}^{2}\right)$ and on the $y$ axis, there are mRNA expressions of ZNT1 $(P=0.002)(\mathbf{a}), Z N T 6(P=0.03)(\mathbf{b})$. Expression is expressed as $\log _{2}$ of the ratio of sample signal to the reference signal Each dot represents one individual. Line represents bestfitted line using regression. BMI, body mass index. 

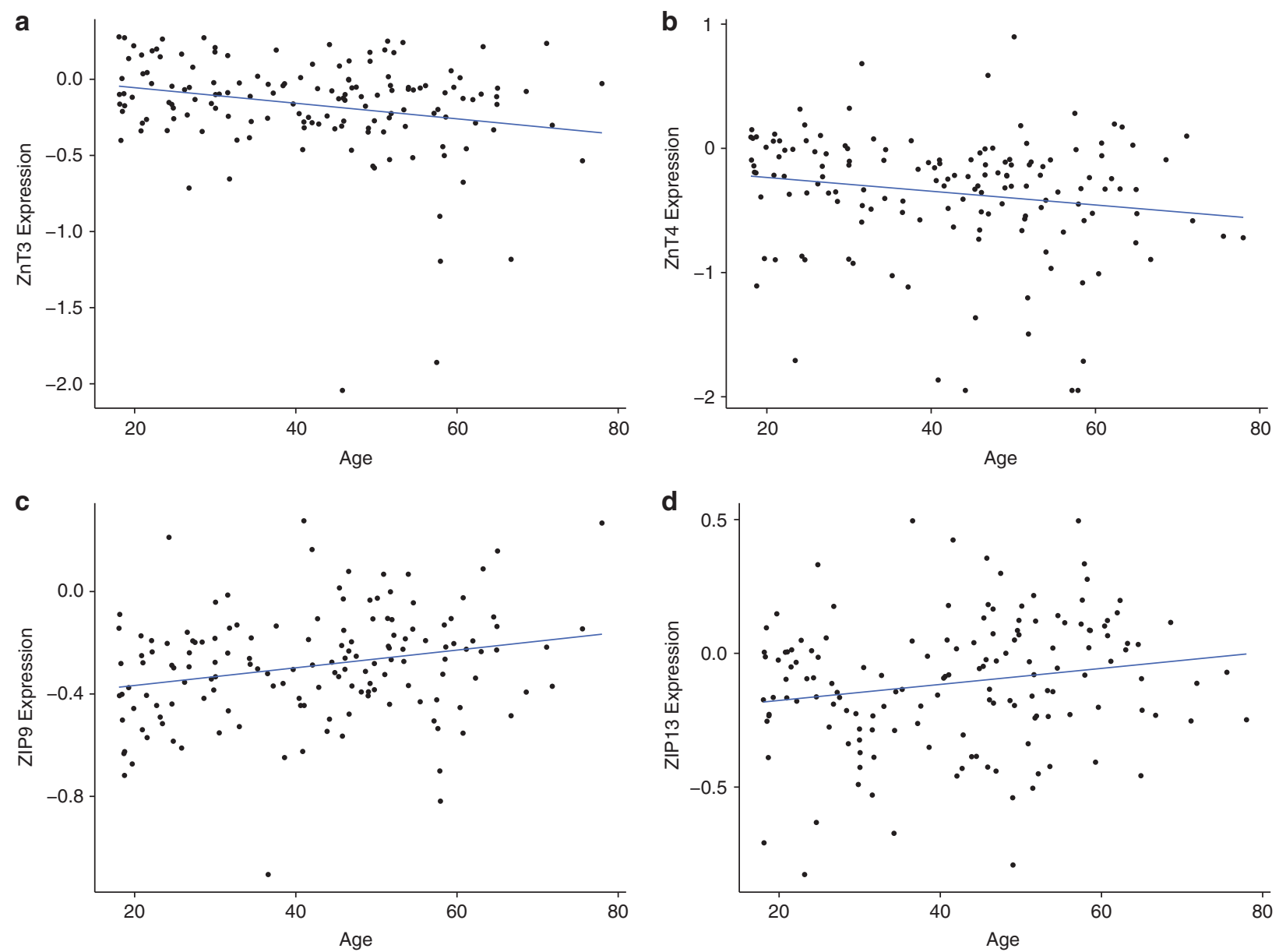

Figure 2. (a-d) On the $x$ axis, Age (years) and on the $y$ axis, there are mRNA expressions of ZNT3 $(P<0.005)(\mathbf{a})$ and ZNT4 $(P=0.038)(\mathbf{b}), Z$ IP9 $(P=0.0024)(\mathbf{c})$ and ZIP13 $(P=0.0226)(\mathbf{d})$. Expression levels are measured as $\log _{2}$ of the ratio of sample signal to the reference signal. Each dot represents one individual. Line represents best-fitted line using regression.
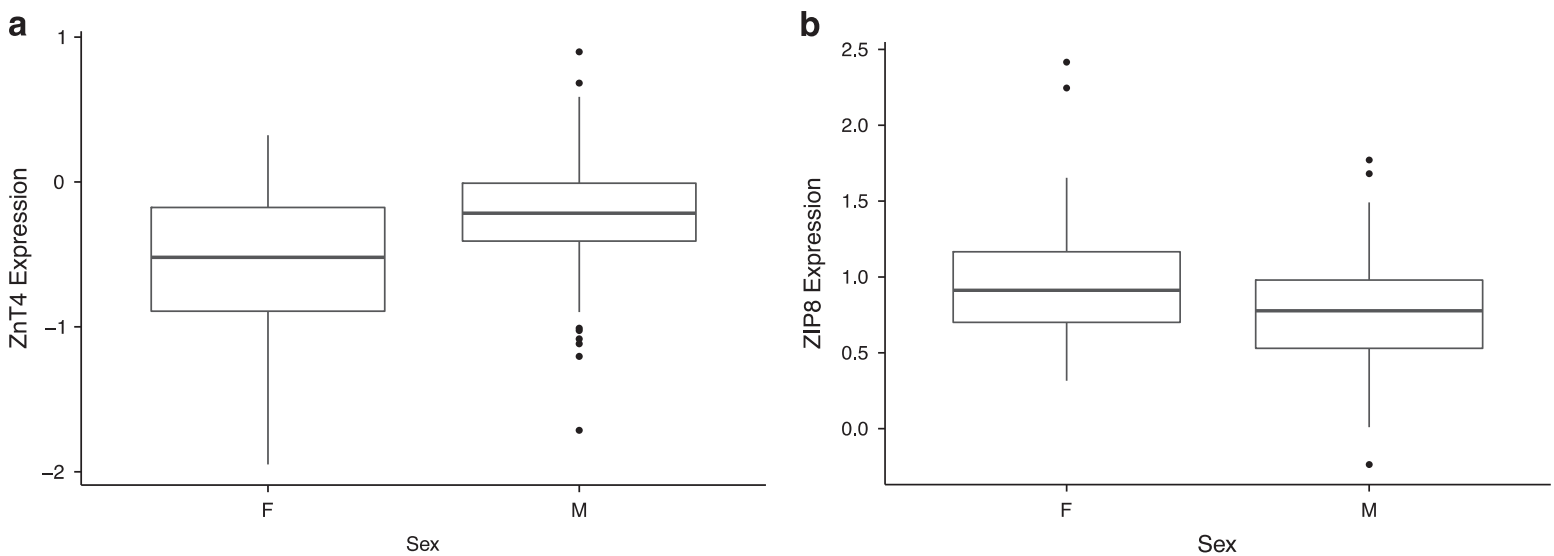

Figure 3. ( $\mathbf{a}$ and $\mathbf{b}$ ) On the $y$ axis, mRNA expression of ZnT4 (a) and ZIP8 (b). F, female; M, male. For each group, bold line represents median; box is upper and lower quantile; and whiskers are upper and lower extreme. Expression levels are measured as log $\operatorname{lof}_{2}$ of the ratio of sample signal to the reference signal.

groups, we found that African Americans displayed a statistically, significantly higher expression of ZIP14 $(t(137.882)=-3.4778$, $P=0.0007$; Figure $4 a$ ), as well as a statistically significant lower expression of three members of the SLC3OA family, that is, ZNT6 $(t(92.96)=3.7504, P=0.003$; Figure $4 b)$, and two of the SLC39A genes, that is, ZIP4 $(W=3511, P=0.001)$ and ZIP7 $(t(113.358)=$ 3.1329, $P=0.0022$; Figures $4 c$ and $d)$.

\section{DISCUSSION}

The analysis of the mRNA expression of the entire SLC30A family as well as 11 of the 14 SLC39A genes in the present study provides new insight into the intracellular zinc regulation in the human brain. Our analyses confirm a previous study ${ }^{30}$ that ZNT3 downregulation is indeed a feature of human aging, accompanied 


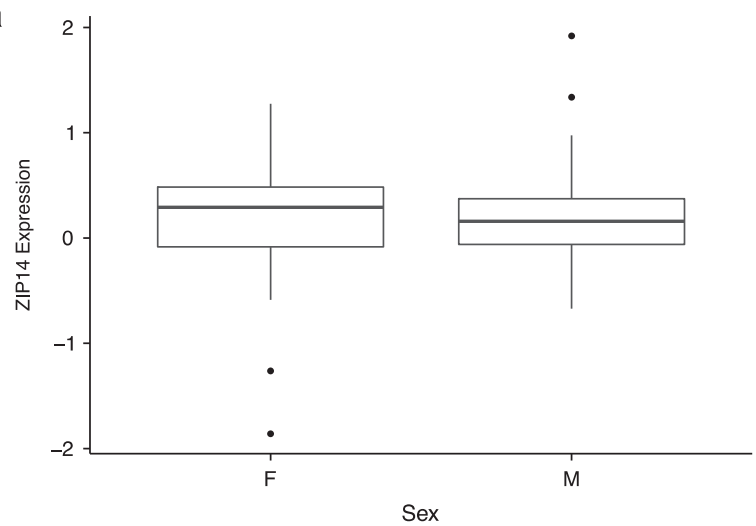

C

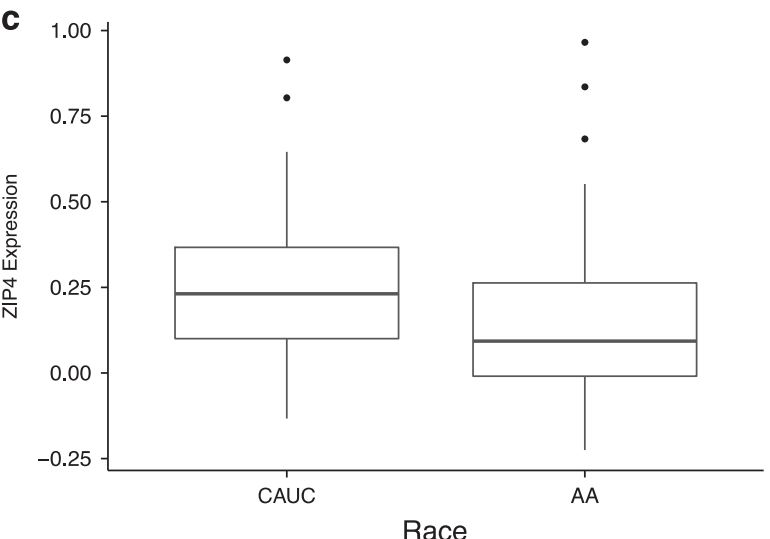

b

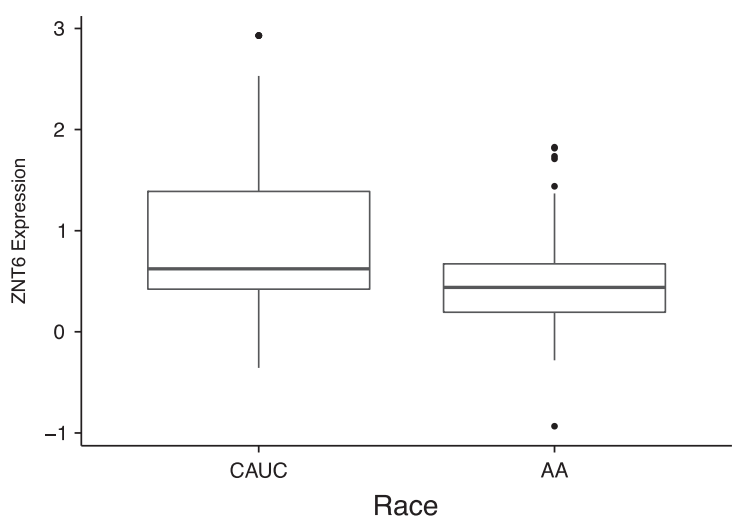

d

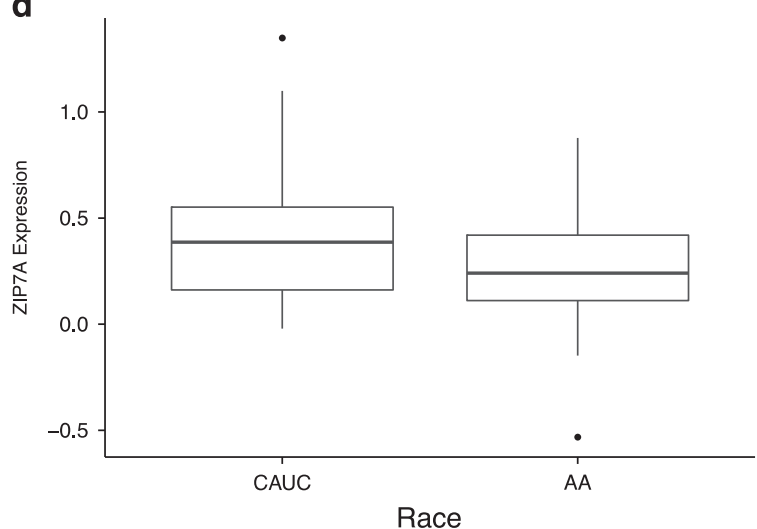

Figure 4. (a-d) On the $y$ axis, mRNA expression, ZIP14 (a), ZNT6 (b), ZIP4 (c) and ZIP7A (d). CAUC, Caucasian; AA, African American. For each group, bold line represents median; box is upper and lower quantile; and whiskers are upper and lower extreme. Expression levels are measured as $\log _{2}$ of the ratio of sample signal to the reference signal.

by the novel finding of a downregulation of ZNT4 and upregulation of ZIP1, ZIP9 and ZIP13. Furthermore, we identified an association between increased body weight and altered zinc homeostasis in the brain as increasing BMI correlated with statistically significant decreases in the expression of ZNT1 and ZNT6. Interestingly, each of these zinc transporters previously has been linked to the development of AD. ${ }^{29,30,37,38,40}$

Low plasma zinc in association with obesity is well described. ${ }^{14-18}$ There is scant information about the zinc content of the human brain in relationship to obesity. Genetically obese mice show unaltered or slightly reduced zinc concentrations in the brain. ${ }^{41}$ Previous reports on the ob/ob mice also found that, compared with lean mice, these obese mice had an increased intestinal uptake of zinc. Such increased zinc uptake occurred irrespective of the amount of food ingested, indicating that in this form of obesity, there is an altered intestinal absorption of zinc. $^{41,42}$ It is unclear whether this increased uptake of zinc has a causative role in this form of obesity, or is an epiphenomenon. A later study by Chen et al. ${ }^{43}$ did, however, find that zinc supplementation significantly increased body fat accumulation in both the ob/ob mice and the obese ICR mice. These findings suggest that increased uptake of zinc could have a causative role in obesity. Paradoxically, the obese mice displayed reduced zinc content in most of the body - that is, the skin, muscle and bonedespite the increased zinc uptake. On the other hand, the amount of zinc in liver, adipose tissue and intestines increased in the obese animals, indicating that obesity alters the zinc distribution in the body. ${ }^{41,44}$ In this respect, zinc sequestration in the enlarged liver could have a prominent role. ${ }^{44}$

Plasma zinc constitutes the main readily available source in the body. Hence, obesity-induced hypozincemia will likely result in reduced zinc availability for the brain. Several studies ${ }^{14-16}$ describe a reduced level of circulating zinc in obese individuals from which affect both total zinc levels and mean erythrocyte zinc levels. In morbidly obese eligible for bariatric surgery, as many as $73.9 \%$ were zinc deficient. ${ }^{14}$ Zinc deficiency correlates with elements of the metabolic syndrome such as insulin secretion, ${ }^{15,17,18}$ as well as with diabetes as such in which an increased loss of zinc in the urine is also seen. ${ }^{18}$ In general, an increased plasma volume could contribute to this pattern, as could reduce dietary zinc intake, which have been reported among obese individuals. ${ }^{17}$ As recently reviewed by Takeda et al., ${ }^{45}$ dietary zinc deficiency rarely results in measurable reductions in brain zinc concentrations. Physiologically, on the other hand, the sensitivity of the body to zinc deficiency is reflected by impaired learning and increased production of glucocorticosteroids as seen in several animal studies. ${ }^{32,46-48}$ As described by Stanstead, ${ }^{32}$ several neuropsychological studies indicate that marginal zinc deficiency might affect perception, attention or psychomotor skills in humans and that this can be corrected by zinc alone or in combination with other micronutrients. In addition, a recent study found that zinc supplementation reduced symptoms of depression as registered by the Hamilton Depression Rating Scale and increased plasma-BDNF levels in obese and overweight depressed humans. ${ }^{49}$ Similarly, several studies link zinc supplementation to increased cortical, cerebral and hippocampal levels of BDNF in mice. ${ }^{50-52}$

Obesity in midlife is associated with an increased risk of AD. ${ }^{6-11}$ In some asymptomatic individuals in their late 40s and early 50s, neuropathological examination has discerned early signs of $A D$ pathology ${ }^{53}$ suggesting that the pathological changes associated with AD may begin far earlier than commonly anticipated. Recent 
works of Lowell et al. ${ }^{38}$ have studied alterations in intracellular zinc regulation in relation to the progression from mild cognitive impairment to fulminant AD. Although some variation with anatomical location within the brain was seen, this study indicated that ZNT1 protein expression is increased in the pre-clinical and early stages of $A D$, and subsequently decreases in the late stages. ${ }^{38}$ These findings suggest that dysregulation of intracellular zinc signaling participates in AD development, but in a complex fashion. In addition, a recent study has shown that ZNT1 binds directly to the GluN2A subunit of the NMDA receptor, ${ }^{54}$ suggesting that alterations in the expression of this specific zinc transporter may have functional consequences not directly related to zinc per se. The exact role of ZNT1 in synaptic activity remains to be elucidated, but this ZNT1-GluN2A complex formation appears to be dynamic in nature as the tendency towards such complex formation varies with synaptic activity.

In addition to alterations in ZNT1 expression, ZNT4 and ZNT6 protein levels are upregulated in late AD. ${ }^{37}$ The ZNT4 and ZNT6 proteins transport zinc into the lysosomal and trans-golgi compartments and it has been hypothesized that an upregulation of ZNT4 and ZNT6 would allow excess zinc to be removed from the cytoplasm before doing any harm. ${ }^{55}$ On the other hand, upregulation of ZNT4 and ZNT6 might also reflect the relative increase in glial cells in late AD. In this study, we found that ZNT5 and ZNT6 are significantly downregulated with increasing BMI, suggesting that obesity could potentially affect tightly regulated zinc homeostasis in the brain tissue.

Investigating zinc dyshomeostasis in AD pathology, both increased and reduced levels of cytoplasmatic zinc have been implicated. Intracellular zinc depletion destabilizes microtubules, herby starting a cascade of tau release, hyper-phophorylation and formation of neurofibrillary tangles. ${ }^{34}$ Intracellular zinc excess, occurring as a consequence of Amyloid beta aggregation and reactive oxygen species generation, liberates zinc from metallothionein and may affect mitochondrial function and induce apoptosis. ${ }^{5-59}$ One way to reconcile these seemingly contradictory findings is to suggest that intracelluar zinc must be tightly regulated to avoid adverse molecular consequences.

Other studies have implicated zinc transporters ZNT3 and ZNT10 in $A D .^{29,30,40}$ Here we find that their expression varies with age and $\mathrm{BMI}$, respectively. An age-related ZNT3 downregulation has been reported in an older human population $(n=24)$-age 49-91 years -as well as in aging rodents. ${ }^{30}$ The ZNT3 protein is responsible for the accumulation of zinc in synaptic vesicles and could be involved in memory and learning. ${ }^{28} \mathrm{~A}$ reduction in ZNT3 expression has been found in the brains of AD patients. Moreover, the role of ZNT3 in learning and memory is suggested by agerelated cognitive loss in elderly Znt3 knockout mice. ${ }^{30}$ The investigation of Znt3 gene and protein expression in the SAMP10 age-accelerated mice also found a link between aging, ZNT3 downregulation and reduced zinc content in the brain. ${ }^{60}$ ZNT3 gene downregulation increases senescence in vascular smooth muscle cells and interestingly, ZNT10 has the same effect. ${ }^{61}$ ZNT10 was recently identified in brain tissue and a decrease in ZNT10 expression has been seen in $A D$ brains. ${ }^{40}$ Despite this close relationship between ZNT3 and ZNT10, we do not see an age-related decrease in ZNT10 expression in our study population.

The role of the SLC39A family in aging has not previously been investigated. Here we find that three members of the ZIP family, that is, ZIP1, ZIP9 and ZIP13 are upregulated with increasing age. Of these, ZIP1 is believed to be ubiquitously expressed in the body. ${ }^{62}$ ZIP1 is highly expressed in the hippocampus and in murine studies, and knocking out ZIP1 attenuated seizure-induced neuronal death. ${ }^{63}$ ZIP1 expression can be upregulated by interleukin- 6 and at least in the prostate also is increased by testosterone. ${ }^{62}$ Dietary zinc deficiency mainly affects the subcellular location of ZIP1 leading to an increased presence in the plasma membrane, ${ }^{64}$ highlighting the need for further studies of the protein levels of ZIP1 in the aging brain. Little is known of the function of ZIP9 and ZIP13 in the brain. Recent studies do, however, link ZIP9-mediated zinc signaling to Akt/Erk regulation ${ }^{65}$ and steroid receptor ${ }^{66}$ function in the other tissues. Zip 13 has previously been described as important in human retino-pigmental cells, ${ }^{67}$ although this transporter may, in fact, be important for the transport of other trace metals such as iron as well. ${ }^{68}$

\section{CONCLUSION}

The present study shows that both increasing age and increasing BMI are associated with alterations in the expression of genes mediating intracellular zinc homeostasis in the human brain. Individual members of the ZNT1 and ZIP gene families have differing relationships with increasing age, as mRNA expression of ZNT3 and ZNT4 is downregulated, whereas the expression of ZIP3, ZIP9 and ZIP13 increases. Increasing BMI levels are associated with reduced expression of ZNT1 and ZNT6, which previously have all been implicated in $A D$ pathology. In light of the increasing rates of obesity and $A D$ throughout the world, more studies on the physiological consequences of zinc dyshomeostasis and the combined role of ZIP and ZNT proteins are warranted. In this respect, modern techniques such as next-generation sequencing could give us further knowledge on the role of zinc transporters in $A D$ and obesity.

\section{CONFLICT OF INTEREST}

The authors declare no conflict of interest.

\section{ACKNOWLEDGMENTS}

We thank the families who donated tissue to this research. We are grateful for the vision and generosity of the Lieber and Maltz families who helped make this work possible and we thank The A.P. Møller Foundation for the Advancement of Medical Science and the Lundbeck Foundation, for their contribution to this project. We also thank Amy Deep-Soboslay and Lewellyn B Bigelow, for their contributions in the diagnostic review of the subjects included in this study. We also thank our colleagues Michael Gejl and Tianzhang Ye for valuable scientific discussions.

\section{REFERENCES}

1 WHO. On Ageing and Life Course. Available at http://www.who.int/ageing/about/ facts/en/index.html. Accessed on 20 August 2013.

2 Alzheimer's Association. 2013 Alzheimer's disease facts and figures. Alzheimers Dement 2013; 9: 208-245.

3 WHO. Dementia: A Public Health Priority, 2012; ISBN: 9789241564458.

4 Matsuzaki T, Sasaki K, Tanizaki Y, Hata J, Fujimi K, Matsui Y et al. Insulin resistance is associated with the pathology of Alzheimer disease: the Hisayama Study. Neurology 2010; 75: 764-770.

5 Panza F, Frisardi V, Capurso C, Imbimbo BP, Vendemiale G, Santamato A et al. Metabolic syndrome and cognitive impairment: current epidemiology and possible underlying mechanisms. J Alzheimers Dis 2010; 21: 691-724.

6 Wotton CJ, Goldacre MJ. Age at obesity and association with subsequent dementia: record linkage study. Postgrad Med J 2014; 90: 547-551.

7 Tolppanen AM, Ngandu T, Kareholt I, Laatikainen T, Rusanen M, Soininen $\mathrm{H}$ et al. Midlife and late-life body mass index and late-life dementia: results from a prospective population-based cohort. J Alzheimers Dis 2014; 38: 201-209.

$8 \mathrm{Xu} \mathrm{WL}$, Atti AR, Gatz M, Pedersen NL, Johansson B, Fratiglioni L. Midlife overweight and obesity increase late-life dementia risk: a population-based twin study. Neurology 2011; 76: 1568-1574.

9 Gunstad J, Paul RH, Cohen RA, Tate DF, Gordon E. Obesity is associated with memory deficits in young and middle-aged adults. Eat Weight Disord 2006; 11: e15-e19.

10 Gunstad J, Paul RH, Cohen RA, Tate DF, Spitznagel MB, Gordon E. Elevated body mass index is associated with executive dysfunction in otherwise healthy adults. Compr Psychiatry 2007; 48: 57-61. 
11 Whitmer RA, Gunderson EP, Barrett-Connor E, Quesenberry CP, Yaffe K. Obesity in middle age and future risk of dementia: a 27 year longitudinal population based study. BMJ 2005; 330: 1360.

12 WHO. WHO Factsheet. Available at http://www.who.int/mediacentre/factsheets/ fs311/en/. Accessed on 20 August 2015.

13 Finucane MM, Stevens GA, Cowan MJ, Danaei G, Lin JK, Paciorek CJ et al. National regional, and global trends in body-mass index since 1980: systematic analysis of health examination surveys and epidemiological studies with 960 country-years and 9.1 million participants. Lancet 377: 557-567.

14 de Luis DA, Pacheco D, Izaola O, Terroba MC, Cuellar L, Cabezas G. Micronutrient status in morbidly obese women before bariatric surgery. Surg Obes Relat Dis 2013; 9: 323-327.

15 Suliburska J, Cofta S, Gajewska E, Kalmus G, Sobieska M, Samborski W et al. The evaluation of selected serum mineral concentrations and their association with insulin resistance in obese adolescents. Eur Rev Med Pharmacol Sci 2013; 17: 2396-2400.

16 Garcia OP, Long KZ, Rosado JL. Impact of micronutrient deficiencies on obesity. Nutr Rev 2009; 67: 559-572.

17 Costarelli L, Muti E, Malavolta M, Cipriano C, Giacconi R, Tesei S et al. Distinctive modulation of inflammatory and metabolic parameters in relation to zinc nutritional status in adult overweight/obese subjects. J Nutr Biochem 2010; 21: 432-437.

18 Beletate V, El Dib R, Atallah A. Zinc supplementation for the prevention of type 2 diabetes mellitus. Cochrane Database Syst Rev 2007.

19 Luchsinger JA, Tang MX, Shea S, Mayeux R. Hyperinsulinemia and risk of Alzheimer disease. Neurology 2004; 63: 1187-1192.

$20 \mathrm{Xu}$ WL, von Strauss E, Qiu CX, Winblad B, Fratiglioni L. Uncontrolled diabetes increases the risk of Alzheimer's disease: a population-based cohort study. Diabetologia 2009; 52: 1031-1039.

21 Frederickson CJ, Suh SW, Silva D, Frederickson CJ, Thompson RB. Importance of zinc in the central nervous system: the zinc-containing neuron. J Nutr 2000; 130: 1471S-1483S.

22 Stoltenberg M, Bush Al, Bach G, Smidt K, Larsen A, Rungby J et al. Amyloid plaques arise from zinc-enriched cortical layers in APP/PS1 transgenic mice and are paradoxically enlarged with dietary zinc deficiency. Neuroscience 2007; 150: 357-369.

23 Danscher G, Jensen KB, Frederickson $\mathrm{CJ}$, Kemp K, Andreasen A, Juhl $\mathrm{S}$ et al. Increased amount of zinc in the hippocampus and amygdala of Alzheimer's diseased brains: a proton-induced X-ray emission spectroscopic analysis of cryostat sections from autopsy material. J Neurosci Methods 1997; 76: 53-59.

24 Religa D, Strozyk D, Cherny RA, Volitakis I, Haroutunian V, Winblad B et al. Elevated cortical zinc in Alzheimer disease. Neurology 2006; 67: 69-75.

25 Wenstrup D, Ehmann WD, Markesbery WR. Trace element imbalances in isolated subcellular fractions of Alzheimer's disease brains. Brain Res 1990; 533: 125-131.

26 Panayi AE, Spyrou NM, Iversen BS, White MA. Part P. Determination of cadmium and zinc in Alzheimer's brain tissue using inductively coupled plasma mass spectrometry. J Neurol Sci 2002; 195: 1-10.

27 Lyubartseva G, Lovell MA. A potential role for zinc alterations in the pathogenesis of Alzheimer's disease. Biofactors 2012; 38: 98-106.

28 Linkous DH, Flinn JM, Koh JY, Lanzirotti A, Bertsch PM, Jones BF et al. Evidence that the ZNT3 protein controls the total amount of elemental zinc in synaptic vesicles. J Histochem Cytochem 2008; 56: 3-6.

29 Beyer N, Coulson DT, Heggarty S, Ravid R, Hellemans J, Irvine GB et al. Zinc transporter mRNA levels in Alzheimer's disease postmortem brain. J Alzheimers Dis 2012; 29: 863-873.

30 Adlard PA, Parncutt JM, Finkelstein DI, Bush Al. Cognitive loss in zinc transporter-3 knock-out mice: a phenocopy for the synaptic and memory deficits of Alzheimer's disease? J Neurosci 2010; 30: 1631-1636.

31 Vergnano AM, Rebola N, Savtchenko LP, Pinheiro PS, Casado M, Kieffer BL et al. Zinc dynamics and action at excitatory synapses. Neuron 2014; 82: 1101-1114.

32 Sandstead HH. Subclinical zinc deficiency impairs human brain function. $J$ Trace Elem Med Biol 2012; 26: 70-73.

33 Lee JY, Cole TB, Palmiter RD, Suh SW, Koh JY. Contribution by synaptic zinc to the gender-disparate plaque formation in human Swedish mutant APP transgenic mice. Proc Natl Acad Sci USA 2002; 99: 7705-7710.

34 Linkous DH, Adlard PA, Wanschura PB, Conko KM, Flinn JM. The effects of enhanced zinc on spatial memory and plaque formation in transgenic mice. J Alzheimers Dis 2009; 18: 565-579.

35 Craddock TJ, Tuszynski JA, Chopra D, Casey N, Goldstein LE, Hameroff SR et al. The zinc dyshomeostasis hypothesis of Alzheimer's disease. PLoS One 2012; 7: e33552.

36 Szewczyk B. Zinc homeostasis and neurodegenerative disorders. Front Aging Neurosci 2013; 5: 33.

37 Smith JL, Xiong S, Markesbery WR, Lovell MA. Altered expression of zinc transporters -4 and -6 in mild cognitive impairment, early and late Alzheimer's disease brain. Neuroscience 2006; 140: 879-888.
38 Lovell MA, Smith JL, Xiong S, Markesbery WR. Alterations in zinc transporter protein-1 (ZnT-1) in the brain of subjects with mild cognitive impairment, early, and late-stage Alzheimer's disease. Neurotox Res 2005; 7: 265-271.

39 Colantuoni C, Lipska BK, Ye T, Hyde TM, Tao R, Leek JT et al. Temporal dynamics and genetic control of transcription in the human prefrontal cortex. Nature 2011; 478: $519-523$.

40 Bosomworth HJ, Adlard PA, Ford D, Valentine RA. Altered expression of ZnT10 in Alzheimer's disease brain. PLoS One 2013; 8: e65475.

41 Kennedy ML, Failla ML. Zinc metabolism in genetically obese (ob/ob) mice. J Nutr 1987; 117: 886-893.

42 Fernandez-Lopez JA, Esteve M, Rafecas I, Remesar X, Alemany M. Management of dietary essential metals (iron, copper, zinc, chromium and manganese) by Wistar and Zucker obese rats fed a self-selected high-energy diet. Biometals 1994; 7: 117-129.

43 Chen MD, Lin PY, Cheng V, Lin WH. Zinc supplementation aggravates body fat accumulation in genetically obese mice and dietary-obese mice. Biol Trace Elem Res 1996; 52: 125-132.

44 Kennedy ML, Failla ML, Smith JC Jr.. Influence of genetic obesity on tissue concentrations of zinc, copper, manganese and iron in mice. J Nutr 1986; 116: 1432-1441.

45 Takeda A, Nakamura M, Fujii H, Tamano H. Synaptic $\mathrm{Zn}(2+)$ homeostasis and its significance. Metallomics 2013; 5: 417-423.

46 Takeda A. Zinc signaling in the hippocampus and its relation to pathogenesis of depression. Mol Neurobiol 2011; 44: 166-174.

47 Takeda A, Tamano H. Insight into zinc signaling from dietary zinc deficiency. Brain Res Rev 2009; 62: 33-44.

48 Massaro TF, Mohs M, Fosmire G. Effects of moderate zinc deficiency on cognitive performance in young adult rats. Physiol Behav 1982; 29: 117-121.

49 Solati Z, Jazayeri S, Tehrani-Doost M, Mahmoodianfard S, Gohari MR. Zinc monotherapy increases serum brain-derived neurotrophic factor (BDNF) levels and decreases depressive symptoms in overweight or obese subjects: a double-blind, randomized, placebo-controlled trial. Nutr Neurosci 2015; 18: 162-168.

50 Nowak G, Legutko B, Szewczyk B, Papp M, Sanak M, Pilc A. Zinc treatment induces cortical brain-derived neurotrophic factor gene expression. Eur J Pharmacol 2004 492: 57-59.

51 Franco JL, Posser T, Brocardo PS, Trevisan R, Uliano-Silva M, Gabilan NH et al. Involvement of glutathione, ERK1/2 phosphorylation and BDNF expression in the antidepressant-like effect of zinc in rats. Behav Brain Res 2008; 188 316-323.

52 Sowa-Kucma M, Legutko B, Szewczyk B, Novak K, Znojek P, Poleszak E et al. Antidepressant-like activity of zinc: further behavioral and molecular evidence. J Neural Transm 2008; 115: 1621-1628.

53 Braak H, Braak E. Frequency of stages of Alzheimer-related lesions in different age categories. Neurobiol Aging 1997; 18: 351-357.

54 Mellone M, Pelucchi S, Alberti L, Genazzani AA, Di Luca M, Gardoni F. Zinc transporter-1: a novel NMDA receptor-binding protein at the postsynaptic density. J Neurochem 2015; 132: 159-168.

55 Sobieszczanska M, Tubek S, Szygula R, Bunio A. Is the zinc neuroprotective effect caused by prevention of intracellular zinc accumulation? Adv Clin Exp Med 2012; 21: 245-248.

56 Capasso M, Jeng JM, Malavolta M, Mocchegiani E, Sensi SL. Zinc dyshomeostasis: a key modulator of neuronal injury. J Alzheimers Dis 2005; 8: 93-108, discussion 209-215.

57 Untergasser G, Rumpold H, Plas E, Witkowski M, Pfister G, Berger P. High levels of zinc ions induce loss of mitochondrial potential and degradation of antiapoptotic $\mathrm{Bcl}-2$ protein in in vitro cultivated human prostate epithelial cells. Biochem Biophys Res Commun 2000; 279: 607-614.

58 Sensi SL, Rapposelli IG, Frazzini V, Mascetra N. Altered oxidant-mediated intraneuronal zinc mobilization in a triple transgenic mouse model of Alzheimer's disease. Exp Gerontol 2008; 43: 488-492.

59 Hamatake $M$, Iguchi $K$, Hirano $K$, Ishida $R$. Zinc induces mixed types of cell death, necrosis, and apoptosis, in molt-4 cells. J Biochem 2000; 128: 933-939.

60 Saito T, Takahashi K, Nakagawa N, Hosokawa T, Kurasaki M, Yamanoshita O et al. Deficiencies of hippocampal Zn and ZnT3 accelerate brain aging of Rat. Biochem Biophys Res Commun 2000; 279: 505-511.

61 Patrushev N, Seidel-Rogol B, Salazar G. Angiotensin II requires zinc and downregulation of the zinc transporters $\mathrm{ZnT3}$ and $\mathrm{ZnT10}$ to induce senescence of vascular smooth muscle cells. PLoS One 2012; 7: e33211.

62 Jeong J, Eide DJ. The SLC39 family of zinc transporters. Mol Aspects Med 2013; 34 612-619.

63 Qian J, Xu K, Yoo J, Chen TT, Andrews G, Noebels JL. Knockout of Zn transporters Zip-1 and Zip-3 attenuates seizure-induced CA1 neurodegeneration. J Neurosci 2011; 31: 97-104. 
64 Wang F, Dufner-Beattie J, Kim BE, Petris MJ, Andrews G, Eide DJ. Zinc-stimulated endocytosis controls activity of the mouse ZIP1 and ZIP3 zinc uptake transporters. J Biol Chem 2004; 279: 24631-24639.

65 Berg AH, Rice CD, Rahman MS, Dong J, Thomas P. Identification and characterization of membrane androgen receptors in the ZIP9 zinc transporter subfamily: I. Discovery in female atlantic croaker and evidence ZIP9 mediates testosterone-induced apoptosis of ovarian follicle cells. Endocrinology 2014; 155: 4237-4249.

66 Taniguchi M, Fukunaka A, Hagihara M, Watanabe K, Kamino S, Kambe T et al. Essential role of the zinc transporter ZIP9/SLC39A9 in regulating the activations of Akt and Erk in B-cell receptor signaling pathway in DT40 cells. PLoS One 2013; 8: e58022.

67 Leung KW, Liu M, Xu X, Seiler MJ, Barnstable CJ, Tombran-Tink J. Expression of ZnT and ZIP zinc transporters in the human RPE and their regulation by neurotrophic factors. Invest Ophthalmol Vis Sci 2008; 49: 1221-1231.
68 Kowalska K, Bizon A, Zalewska M, Milnerowicz H. The influence of biological and environmental factors on metallothionein concentration in the blood. J Trace Elem Med Biol 2015; 29: 99-103.

cc) (i)

This work is licensed under a Creative Commons Attribution 4.0 International License. The images or other third party material in this article are included in the article's Creative Commons license, unless indicated otherwise in the credit line; if the material is not included under the Creative Commons license, users will need to obtain permission from the license holder to reproduce the material. To view a copy of this license, visit http://creativecommons.org/licenses/ by/4.0/

(c) The Author(s) 2016 